\title{
Diurnal Variability of Peak Expiratory Flow Rate in Healthy Adult Employees of a Medical College of Kathmandu
}

Gita Khakurel', Kalyan Gautam1', Sanat Chalise ${ }^{2}$

\begin{abstract}
Author(s) affiliation
'Department of Physiology, Kathmandu Medical College Public Limited, Duwakot, Bhaktapur, Nepal

${ }^{2}$ Department of Pathology, Kathmandu Medical College Public Limited, Sinamangal, Kathmandu, Nepal
\end{abstract}

\section{Corresponding author}

Gita Khakurel, MBBS, MD

khakurelgita@gmail.com

\section{Submitted}

Sep 28, 2020

\section{Accepted}

Feb 7, 2021

\begin{abstract}
\section{Introduction}

Peak expiratory flow measurement is a simple measure of respiratory capacity to diagnose airflow obstruction and monitor treatment response in patients with pulmonary diseases. But there is wide diurnal variability in its values. The objectives of this study was to determine the diurnal variability of peak expiratory flow rate in healthy adults.
\end{abstract}

\section{Methods}

This cross-sectional study was done in employees of Kathmandu Medical College, Duwakot between March to August 2020. A total of 74 subjects of $30-45$ years were included in the study. After adequate training, subjects were asked to record their own peak expiratory flow five times a day by Mini-Wright peak flow meter. Diurnal variability was expressed as amplitude percent mean and standard deviation percent mean. Data analysis was done by student's unpaired t-test and one-way ANOVA.

\section{Results}

The mean peak expiratory flow rate (in L/min) were lowest in morning (male: $478.75 \pm 45.91$; female: $362.86 \pm 20.51$ ) followed by progressive rise throughout the day and highest at evening (male: $531.88 \pm 43.95$; female: $415.71 \pm 20.97$ ) with slight fall at bedtime (male: $486.88 \pm 46.38$; female: $362.86 \pm 20.51$ ). The difference in peak expiratory flow rate at different time periods was statistically significant in both males and females $(p<0.001)$. The diurnal variability as calculated by amplitude percent mean and standard deviation percent mean were found to be significantly higher in females ( $p=0.001$ and 0.004 respectively).

\section{Conclusion}

There is a variation of peak expiratory flow rate recorded during different time points of the day in healthy adults.

\section{Keywords}

Diurnal variation, peak expiratory flow rate, spirometry 


\section{INTRODUCTION}

$\mathrm{P}$ eak expiratory flow rate (PEFR) is defined as the maximum rate at which a person can blow exhaled air after taking a deep inspiration. There is variation in PEFR values throughout day and night which follows a specific pattern of lowest at early morning and highest at evening. This diurnal variation is seen in healthy individuals and more pronounced in people with asthma., ${ }^{1,2}$ This variability in peak expiratory flow has been indicated as a marker of bronchial hyper-reactivity. ${ }^{3}$

The measurement of airflow by PEFR is relatively a simple and easy procedure to evaluate the pulmonary function. ${ }^{4}$ A diurnal variation of $20 \%$ or more has been regarded as the diagnostic criteria by the National Heart Lung and Blood Institute. ${ }^{5}$ Diurnal changes occurs in close relation with body temperature, oxygen consumption and carbon dioxide production. But these factors could not fully explain the diurnal variation of ventilation. ${ }^{6}$

Most of these studies are done in patient population and adequate data is not available about the diurnal variation in normal individuals in our settings. For understanding etio-pathology of airway diseases it is important to study the variations in airway caliber in healthy subjects. Therefore, the aim of this study is to evaluate the pattern of diurnal variation of PEFR in healthy adults.

\section{METHODS}

This was a cross sectional study conducted on 74 apparently healthy employees of Kathmandu Medical College Public Limited, Duwakot, Bhaktapur between March 2020 to August 2020. The ethical approval for the study was taken from Institutional Review Committee of Kathmandu Medical College Teaching Hospital, Sinamangal. The subjects were selected randomly among employees from the age group of 30-45 years. The nature of the study was explained to the participants and informed written consent was taken for the study. A detailed history and clinical examination was performed to rule out any obvious cardio-pulmonary compromise. The sociodemographic informations such as age, gender, smoking and drinking habits were noted. Subjects with history of smoking, chest and spinal deformity, personal/family history of asthma, chronic obstructive pulmonary diseases were excluded from the study.

The subjects height in centimeter and weight in kilogram was recorded and BMI $\left(\mathrm{kg} / \mathrm{m}^{2}\right)$ was calculated. The PEFR (L/min) was measured with Mini Wright's peak flow meter (Ferraris Pocket peak flow meter). The subjects were trained for measuring their own PEFR in L/min. A previous study suggested that self-recording is reliable to obtain a good reference data. ${ }^{7}$ The peak flow meters with disposable mouthpiece was given to the subject. They were instructed to stand erect and hold the instrument in horizontal position in such a way that the hand did not obstruct the movement of the pointer. The pointer was kept at the lower most level. The nostrils were clipped with nose clipper. They were trained to take a deep breath, put the mouthpiece of the peak flow meter inside the mouth and exhale forcefully. Each time three readings at intervals of approximately 10 seconds each was made. Subjects were asked to record PEF five times a day: on waking, between 9 and $11 \mathrm{am}$, between 2 and 4 pm, between 6 and 8 pm and at bedtime. The subjects were instructed to record the PEFR readings in the chart provided to them. The best of three PEFR readings in a given time was taken for analysis. Each time the subject returned the instrument, the mouth piece of peak flow meter was disinfected by immersing it in 10 $\%$ glutaraldehyde solution for 2 hours and cleaned properly before giving it to next subject. ${ }^{8}$

The data was entered and analyzed using the IBM SPSS Statistics Software version 22.0. The pattern of peak expiratory flow (PEF) variability for each subject was noted and the mean and standard deviation of PEF was calculated. Diurnal variation for individual subject was calculated by using amplitude percent mean (A\%M) and standard deviation percent mean (SD\%M), as per the following formulae.

$\mathrm{A} \% \mathrm{M}=\frac{\text { Highest PEFR of the day-Lowest PEFR of the day }}{\text { Mean PEFR of the day }} \times 100$

$\mathrm{SD} \% \mathrm{M}=\frac{\text { Standard deviation of PEFR of the day }}{\text { Mean PEFR of the day }} \times 100$

The mean PEFR values at different time points were analyzed by one way analysis of variance (ANOVA). The mean values of $\mathrm{A} \% \mathrm{M}$ and SD\%M of peak flow variability were compared in males and females by student's unpaired t test. A $p \leq 0.05$ was considered statistically significant.

\section{RESULTS}

A total of 74 participants were included in the study in which female participants were 42 (56.75 $\%)$ and male participants were 32 (43.24\%). The anthropometric data of study population is shown in Table 1.

The mean PEFR values were lowest in the morning and showed progressive rise throughout the day in both males and females. The highest mean PEFR value observed was $557.50 \pm 50.41$ in males and $438.10 \pm 22.00$ in females in evening at 5-6 pm. The mean PEFR values were statistically significant at different time period in both males and females $(p<0.001)$ (Table 2). 
Table 1. Demographic characteristics of the study population

\begin{tabular}{lcc}
\hline \multirow{2}{*}{ Variable } & \multicolumn{2}{c}{ Gender } \\
\cline { 2 - 3 } & Males $(\mathrm{n}=\mathbf{3 2})$ & Females $(\mathrm{n}=\mathbf{4 2})$ \\
\hline Age (years) & $38.16 \pm 4.10$ & $38.79 \pm 4.45$ \\
Height $(\mathrm{m})$ & $1.69 \pm 0.10$ & $1.58 \pm 0.09$ \\
Weight $(\mathrm{kg})$ & $65.31 \pm 6.97$ & $59.98 \pm 6.77$ \\
BMI $\left(\mathrm{kg} / \mathrm{m}^{2}\right)$ & $22.99 \pm 3.66$ & $24.17 \pm 3.78$ \\
\hline
\end{tabular}

The mean diurnal variation of PEFR calculated as amplitude percent mean (A\%M) and standard deviation percent mean (SD\%M) were significantly higher in females than in males (Table 3).

\section{DISCUSSION}

In the present study, we observed lowest value of PEFR in the early morning followed by a progressive rise throughout the day. The value of PEFR was highest in the evening and again slight fall in the bedtime. This diurnal variation was significantly observed in both males and females. These findings are in accordance with the studies done by Asfaq et $\mathrm{al}^{4}$, Jena et $\mathrm{al}^{9}$ and Aggarwal et al. ${ }^{10}$ Similar characteristics pattern of diurnal variation is also observed in asthmatic patients with a low peak expiratory flow rate early in the morning followed by increased value during the day. ${ }^{11}$

The biological clock which is responsible for this diurnal variation has not been identified..$^{12}$ However, Singh $V$ et al suggested that long term periodic exposure to air pollutants can lead to increased PEFR variability in healthy subjects. ${ }^{13}$ It is suggested that if the sleep pattern changes, it takes about 2-3 days to adjust to the diurnal rhythm. After the adjustment the highest PEFR value is observed around the midpoint of the awake period. ${ }^{14}$

The diurnal variability in the present study was calculated and expressed as amplitude mean percent $(\mathrm{A} \% \mathrm{M})$ and standard deviation percent (SD\%M). Higgins et al concluded that $\mathrm{A} \% \mathrm{M}$ and $\mathrm{SD} \% \mathrm{M}$ provide the best means of expressing PEF variability for epidemiological purposes. ${ }^{15}$ In the present study the value of $\mathrm{A} \% \mathrm{M}$ and $\mathrm{SD} \% \mathrm{M}$ are higher than the studies done by Goyal et al $(7.55 \pm 4.1 \text { and } 2.79 \pm 1.42)^{16}$ and Aggarwal et al
Table 3. Diurnal variation of PEFR expressed as $A \% M$ and SD\%M in males and females

\begin{tabular}{lccc}
\hline \multirow{2}{*}{ Variable } & \multicolumn{2}{c}{ Gender } & \\
\cline { 2 - 3 } & Males $(\boldsymbol{n}=\mathbf{3 2})$ & Females $(\mathrm{n}=\mathbf{4 2})$ & \\
\hline $\mathrm{A} \% \mathrm{M}$ & $16.07 \pm 2.61$ & $19.60 \pm 5.04$ & 0.001 \\
$\mathrm{SD} \% \mathrm{M}$ & $6.77 \pm 1.39$ & $8.06 \pm 2.15$ & 0.004 \\
\hline
\end{tabular}

$(7.23 \pm 3.48 \text { and } 2.98 \pm 1.31)^{10}$ respectively. These differences in the diurnal variation of PEFR may be due to alterations in the sample size, timing of measurement and/or age groups. Our findings indicated that there was a significant difference in diurnal variation of PEF between the two sexes with $\mathrm{A} \% \mathrm{M}$ and $\mathrm{SD} \% \mathrm{M}$ being higher in females. Similar findings of higher $\mathrm{A} \% \mathrm{M}$ in females was observed in study done by Jena SK et $\mathrm{al}^{9}$ and Higgins BG et al. ${ }^{17}$ Whereas studies done by Thaman et al ${ }^{18}$ Aggarwal et a $\left.\right|^{10}$ reported that there is no difference in the diurnal variation of PEFR between males and females.

Ideally, PEFR measurements should be taken frequently during the 24 hour period to show the reliable diurnal variability. ${ }^{19}$ In the present study we have taken PEFR readings five times a day so as to assess the diurnal variation. It has been suggested that at least four readings per day which is evenly spaced during the waking hours should be done to obtain a reliable value of peak expiratory flow rate diurnal variation. ${ }^{14}$

There are some limitations of the study. Firstly, the sample size was relatively small and included only adults of single organization. We could have got better reference range if large sample was included. Secondly, we did not study PEFR in asthmatics patients which would have helped in comparing the differences of diurnal variation in healthy and diseased subjects. Thirdly, the values of PEFR is effort-dependent which may have resulted in intrasubject variability.

\section{CONCLUSION}

The study concludes that there is significant diurnal variation of PEFR in males and females. This provides the baseline reference data of diurnal variation of PEFR in healthy adults in our settings.

Table 2. Mean PEFR values at different time intervals in males and females

\begin{tabular}{lcccccc}
\hline \multirow{2}{*}{ Gender } & \multicolumn{5}{c}{ Peak expiratory flow rate (L/min) } & \\
\cline { 2 - 6 } & On waking & $\begin{array}{c}\text { Between } \\
\text { 9 and 11 am }\end{array}$ & $\begin{array}{c}\text { Between } \\
\text { 2 and 4 pm }\end{array}$ & $\begin{array}{c}\text { Between } \\
\text { 6 and 8 pm }\end{array}$ & At bedtime & p-value \\
\hline Male $(\mathrm{n}=32)$ & $478.75 \pm 45.91$ & $503.13 \pm 50.95$ & $531.88 \pm 43.95$ & $557.50 \pm 50.41$ & $486.88 \pm 46.38$ & $<0.001$ \\
Female $(\mathrm{n}=42)$ & $362.86 \pm 20.51$ & $391.19 \pm 20.26$ & $415.7 \pm 20.97$ & $438.10 \pm 22.00$ & $373.10 \pm 18.00$ & \\
\hline
\end{tabular}




\section{ACKNOWLEDGEMENTS}

We would like to thank the employees of Kathmandu Medical College, Duwakot, Bhaktapur for their active participation in the study without whom the study could not be accomplished.

\section{CONFLICT OF INTEREST}

None declared.

\section{REFERENCES}

1. Jayapal J. Evaluation of diurnal variation in peak expiratory flow rates in healthy Indian adult male and female subjects. Trop J Med Res. 2016; 19:11-13

2. Aggarwal AN, Gupta D, Kumar V, et al. Assessment of diurnal variability of peak expiratory flow in stable asthmatics. J Asthma. 2002; 39:487-91.

3. Higgins $B G$, Britton JR, Chinn $S$, et al. Comparison of bronchial reactivity and peak expiratory flow variability measurements for epidemiologic studies. Am Rev Respir Dis. 1992; 145:588-93.

4. Ashfaq $S$, Saeed M. Diurnal variation in peak expiratory flow rates of healthy young adults. PJMHS. 2009;3 :125-127.

5. Jamison JP, Mckinley RK. Validity of peak expiratory flow rate variability for the diagnosis of asthma. Clin Sci. 1993; 85:367-371.

6. Mortola JP. Breathing around the clock: an overview of the circadian pattern of respiration. Eur J Appl Physiol. 2004; 91:119-129

7. Johnston I, Anderson HR, Patel S. Variability of peak flow in wheezy children. Thorax. 1984; 39:583-7.

8. Mathur N, Rastogi SK, Kesavachandran C, et al. Prediction models for peak expiratory flow rates in North Indian male population based on ordinary and weighted least square estimation. Current Science. 2007; 93 (7):959-963.

9. Jena SK, Mohanty A, Mania RN, et al. Diurnal variation of peak expiratory flow rate in healthy young adults: A gender-based study. J Med Soc. 2017; 31:104-8.

10. Aggarwal AN, Gupta D, Chaganti S, et al. Diurnal variation in peak expiratory flow in healthy young adults. Indian J Chest Dis Allied Sci. 2000; 42:15-9.

11. Medarov BI, Pavlov VA, Rossoff L. Diurnal variations in human pulmonary function. Int J Clin Exp Med. 2008; 1 (3):267-273.

12. Hetzel MR. The pulmonary clock. Thorax 1981; 36:481-486

13. Singh $V$, Khandelwal $R$, Gupta AB. Effect of air pollution on peak expiratory flow rate variability. J Asthma. 2003; 40:81-86.

14. Jindal SK, Aggarwal AN, Gupta D. J Asthma. 2002 ;39:363-373.

15. Higgins BG, Britton JR, Chinn $S$, et al. The distribution of peak expiratory flow variability in a population sample. Am Rev Respir Dis. 1989;140 (5): 1368-72.

16. Goyal M, Goel A, Kumar P, et al. Circadian rhythm of peak expiratory flow rate in healthy north Indian men. Indian J Physiol Pharmacol 2008;52 (1):64-68.

17. Higgins BG, Britton JR, Chinn $S$, et al. Factors affecting peak expiratory flow variability and bronchial reactivity in a random population sample. Thorax. 1993 Sep; 48(9): 899-905.

18. Thaman RG, Girgla KK, Arora GP. Circadian peak expiratory flow rate variability in healthy North Indian geriatric population. JIACM 2010; 11 (3); 195-8.

19. Gupta D, Aggarwal AN, Chaganti S, et al. Reducing the number of daily measurements results in poor estimation of diurnal variability of peak expiratory flow in healthy individuals. Journal of Postgraduate Medicine 2000;46 (4):262-264. 